\title{
EDITORIAL
}

\section{Use of peak flow-based self-management plans by adult asthmatic patients}

\author{
D. Fishwick*, R. Beasley*
}

It is intriguing to reflect on the major changes that have occurred over the last few decades in the recommended role of peak flow monitoring in the clinical management of asthma. From the situation in the late 1970s, when the use of peak flow recordings as part of an asthma self-management strategy was raised hypothetically [1], the recent International Consensus Report on the Diagnosis and Management of Asthma now recommends that peak flow monitoring is essential for the objective assessment of asthma severity, and that a peak flowbased management plan should be used by most asthmatic patients [2]. Despite these recommendations, some remain unconvinced as to the importance of the widespread use of peak flow monitoring and its incorporation into asthma self-management plans.

In this editorial, we briefly review the studies on which the current recommendations are based, and comment on three articles published in this edition of the European Respiratory Journal, which provide valuable additional knowledge in this area [3-5]. Finally, we attempt to bring together the published literature to propose practical and simple guidelines for the use of peak flow-based selfmanagement plans by adult asthmatic patients.

\section{Objective versus subjective assessment of asthma severity}

The rationale on which the use of peak flow monitoring is based is that it provides an objective measurement of the degree of airflow obstruction for the significant proportion of patients who would otherwise have difficulty recognizing changes in asthma severity. This problem was illustrated by RUBINFELD and PAIN [6] 20 yrs ago when they observed that there was a considerable variation in the severity of breathlessness for any particular degree of airways obstruction, and that a significant number of chronic adult asthmatics had trivial symptoms despite marked airflow obstruction. In the clinical situation of worsening asthma provoked by bronchial challenge testing, about one quarter of their group of patients had minimal or no symptoms despite forced expiratory volume in one second (FEV1) values $<50 \%$ of those predicted. It was not possible from this study to identify the subgroup in whom the poor perception of asthma severity was a particular problem.

However, a later study [7] observed that it was the most severe asthmatic patients, with baseline airway obstruction and the greatest degree of bronchial hyperreactivity,

Correspondence: R. Beasley, *Dept of Medicine, Wellington School of Medicine, P.O. Box 7343, Wellington South, Wellington, New Zealand. who had the worst perception of the severity of airflow obstruction. The authors suggested that it was the asthmatic patients who were developing repeated episodes of severe bronchospasm in response to provoking stimuli who were experiencing less marked symptoms with such episodes. The concept of temporal adaptation was raised as a mechanism whereby such patients were able to reduce the sensory intensity of the symptoms they were experiencing.

Complementing these laboratory-based investigations are two recent general practice-based studies $[8,9]$, which have confirmed the poor relationship between peak flows and symptoms. Using visual analogue scores to determine the perceived severity of asthmatic symptoms, one study [8] found that $60 \%$ of patients with asthma were poor discriminators between high and low peak flow rates. A significant proportion of patients had consistently low scores despite large changes in peak flow, whereas others showed a wide scatter of scores at any given peak flow rate. In the other study [9], which examined the frequency of symptoms rather than their severity, the morning peak flow was observed to be an unreliable predictor of the symptoms subsequently experienced by asthmatic patients during the day.

However, other studies have emphasized that peak flow monitoring should not be undertaken in isolation from symptoms. For example, in the retrospective analysis of peak flow charts of adult asthmatics who had recently experienced a severe attack of asthma, it was observed that peak flow monitoring may fail to detect some exacerbations characterized by symptoms severe enough to justify a course of oral steroids [10].

In severe asthma, the magnitude of the change in peak expiratory flow (PEF) or FEV1 following high-dose inhaled beta-agonist therapy has been shown to be the most important and useful method of assessment [11, 12]. Such measurements are more reliable than symptoms or other clinical and laboratory parameters as indicators of asthma severity and the requirement for subsequent management, such as the likelihood of needing hospital admission.

Focusing on the recovery from a severe asthmatic attack, McFADDEN et al. [13] reported that adult patients with asthma were essentially asymptomatic and free of physical signs of airways obstruction when the FEV1 returned to about two thirds of the predicted values. Even when the FEV1 has returned to near expected values, it is known that improvement in bronchial responsiveness after an acute attack of asthma may lag well behind [14].

The paper of UwyYed et al. [3], in this issue of the European Respiratory Journal, has specifically examined 
the influence of underlying asthma severity on the relationship between peak flow measurements and symptoms. In this study of predominantly teenaged children, the relationship between ambulatory measurements of peak flow, symptoms and bronchodilator use was closest for those with chronic severe asthma, defined by the requirement for daily prophylaxis with inhaled corticosteroids at doses $>500 \mu \mathrm{g} \cdot$ day $^{-1}$. There was a significant correlation between peak flow, symptoms and bronchodilator use in $70-80 \%$ of this severe group, compared with $22-55 \%$ in the mild and moderate groups. These findings contrast with those of other studies, which have demonstrated either no difference in perception in relation to asthma severity $[6,8]$, or a worse perception in patients with a greater degree of bronchial hyperresponsiveness [7]. The reasons for these differing results are not clear.

These authors also made a number of observations that are of clinical relevance to practising physicians. They reported that peak flow measurements, expressed as percentage of predicted normal values, correlated more closely with symptoms and bronchodilator use than when expressed as diurnal peak flow variation. This suggests that the use of peak flow recordings as a percentage of predicted values is not only simpler to derive but is also more informative than the calculation of peak flow variability.

Another observation made by the authors was that differences may exist between peak flow values recorded from domiciliary peak flow meters and those recorded by spirometry. This finding indicates that peak flow results from different devices are not necessarily interchangeable and reinforces the clinical practice of advising asthmatics to record their peak flow measurements (whenever possible) on their own meters.

The authors also observed that there was little or no correlation between lung function measured by spirometry every 2 weeks in the laboratory, and peak flow, symptoms or bronchodilator use recorded daily during the previous 2 week period. This illustrates the major limitation of single lung function measurements for a disease which, by definition, is characterized by reversible airflow obstruction. This also suggests that such clinicbased spirometry is no substitute for regular domiciliary peak flow recordings, particularly during periods of unstable asthma.

Taken together, the available studies provide considerable evidence to support a major role for peak flow monitoring by adult asthmatic patients, to objectively assess the degree of lung function impairment in asthma. Peak flow monitoring appears to be particularly valuable in patients with chronic severe asthma, and when used in the situation of acute severe attacks, in which the magnitude of the change in peak flow in response to inhaled beta-agonist therapy is especially informative. However, these studies also suggest that for optimal benefit, peak flow monitoring should be undertaken in conjunction with the identification and interpretation of key symptoms.

\section{Incorporation of peak flow monitoring in asthma management}

The next issue to address is the role of peak flow monitoring by asthmatic patients. Should it be undertaken in isolation from overall asthma management or be an integral part of a self-assessment and self-management strategy developed by the asthmatic patients and their physicians? The futility of the former approach is illustrated in the paper by VeRSCHELDEN et al. [4] in this issue of the European Respiratory Journal, which investigates the compliance and accuracy of twice daily self-assessment of peak flow by stable adult asthmatic patients during a 3 month period. They observed that only just over a quarter of patients had good compliance, as judged by the accurate measurement and subsequent documentation of peak flow rates.

These findings are not surprising, as it is analogous to recommending to diabetic patients that they measure their blood sugar levels, without advising them of the rationale for such measurements, and without providing them with the knowledge or self-management skills to alter the dose of insulin according to the blood glucose levels obtained. In this situation, compliance would also be expected to be poor, despite the clear benefit of measuring blood glucose levels as part of an overall diabetic self-management strategy [15]. Similarly, if patients are given the ability to interpret their peak flow values in order to identify deteriorating asthma and adjust their treatment accordingly, it is likely that their compliance would improve as there would be some logical basis for undertaking the peak flow monitoring. Another corollary to consider is the interpretation of studies which have documented poor compliance with inhaled corticosteroid therapy [16]. This does not mean that inhaled corticosteroids have no place in the management of asthma, but rather that the reasons for the regular use of inhaled corticosteroid therapy should be stressed to the patient as part of an overall education and management approach.

\section{Efficacy of peak flow-based management plans}

With the acceptance of the need to incorporate peak flow monitoring into an overall self-assessment and selfmanagement strategy, it is necessary to review the efficacy of such an approach. Assessment of the efficacy of asthma self-management plans has been limited both by a paucity of controlled studies and by investigations being undertaken in asthmatic populations with mild asthma, in whom it is inherently difficult to determine changes in morbidity.

In two large controlled studies from the United States an intensive out-patient treatment programme, incorporating a loosely structured asthma self-management plan involving both symptom assessment and peak flow monitoring, resulted in major improvements in morbidity and the requirement for in-patient hospital care [17, 18]. For example, the out-patient programme for disadvantaged adult asthmatics in New York [18] resulted in a threefold reduction in the hospital readmission rate and a twofold reduction in the hospital day-use rate, with the improvements being maintained during a 3 year followup period.

A number of uncontrolled studies of structured peak flow and/or symptom-based asthma self-management plans [19-24] have also shown significant improvements in asthma morbidity and requirement for acute medical services, and in some, improvements in lung function. 
In general, the greatest improvements have been observed in those groups of asthmatic patients who had unstable asthma at the time of the intervention.

More recently, in four randomized, controlled studies, contrasting results have been reported with the introduction of a peak flow-based asthma self-management plan [25-28]. In the two out-patient-based studies, marked improvement in morbidity, requirement for emergency medical treatment and quality of life were observed $[25,26]$. In the two other studies $[27,28]$, similar marked improvements were not observed, perhaps relating to the mild nature of the subjects' asthma and the specific selfmanagement strategies employed.

The study by AYREs et al. [5] in this issue of the Journal provides additional evidence of efficacy of a management plan based on peak flow monitoring and inhaled corticosteroid therapy. Both treatment groups regularly recorded peak flow rates, with their inhaled corticosteroid therapy modified in accordance with changes in peak flow, which was undertaken either by the patient at home, or by the doctor on regular clinic review. Both groups showed similar marked reductions in asthma morbidity, with a $75 \%$ decrease in the number of sleep-disturbed nights, comparable with the $84 \%$ reduction with a similar peak flow-based plan previously studied in a group of unstable asthmatic patients [19]. However, in contrast to other studies, the improvement in morbidity was not associated with an improvement in lung function. Of relevance to the issue of compliance, the vast majority of the patients preferred self-management to their previous management system and expressed a wish to continue using the self-management plan.

Taken together, these studies suggest that a peak flow and symptom-based asthma self-management system is likely to be efficacious in the treatment of asthmatic patients, with the magnitude of the improvement dependent on the characteristics of the asthmatic population treated, the particular features of the plan, and the manner in which the plan is introduced as part of an overall educational and management programme.

\section{Structure of a peak flow-based self-management plan}

The final issue to consider is what steps and interventions the self-management plan should contain. In many respects, the real importance of the study by AYRES et al. [5] is the contribution it makes to our understanding of this issue.

Most self-management plans have four general stages in which treatment guidelines are recommended in response to changes in asthma severity, which are recognized by peak flow measurements and the interpretation of key symptoms [29]. The first stage provides guidelines for regular maintenance therapy; the second stage generally recommends an increase in the dose of inhaled corticosteroid in response to deteriorating asthma; the third stage recommends the introduction of oral prednisone and medical review with the recognition of severe asthma; and the fourth stage recommends seeking emergency medical assistance in the situation of a life-threatening attack. Of these stages, evidence to support the recommendations for the second stage is weakest [30], although the practice of using increasing doses of inhaled corticosteroids to treat increasingly severe asthma is well-established [2]. The study be AYREs et al. [5] provides support for this recommended practice of varying the dose of inhaled corticosteroids in response to changes in asthma severity in the context of an asthma selfmanagement plan. It could be argued that their results also indicate that patients' self-assessment of asthma severity is the fundamental requirement in determining the ideal regular dose of inhaled corticosteroid therapy. This view is supported by the observation that all patients were prescribed prophylactic therapy for 3 months prior to enrolment, and that it was only with the incorporation of inhaled corticosteroid therapy in an overall management plan that a major reduction in morbidity was achieved.

The findings of this study are informative in a number of other respects. The observation that improvements resulting from six weekly clinic-based medical reviews were similar to those from patient-initiated self-management, suggests that the major advantages from the plan result from appropriate long-term management reducing the frequency of severe attacks, rather than through the treatment of the severe attacks per se.

The peak flow levels designated for changes in treatment were also of interest; levels of $>85 \%$ predicted were set for halving the dose of inhaled corticosteroids; a change to $<85 \%$ or $<70 \%$ was used for consecutive doubling of the dose of inhaled corticosteroids; and $<60 \%$ for starting a course of oral prednisone. These values were somewhat higher than those chosen for the original structured peak flow plans [19, 20], and reflect the growing consensus that the higher values are more appropriate, reducing the risk of underestimating asthma severity in the situation of worsening asthma.

Finally, before suggesting guidelines for the use of peak flow-based asthma self-management plans, it is relevant to mention two recent studies, which provide information as to the way in which such plans are used by asthmatic patients. In the randomized, controlled study from Finland in which guided self-management led to a $>50 \%$ reduction in the number of asthma incidents when compared with traditional treatment, the possible associations between symptoms, peak flow values and patients' adherence to instructions were explored [25]. This analysis identified that the instruction to double the dose of inhaled corticosteroid when the peak flow fell to $<85 \%$ was followed on $62 \%$ of occasions. On most of these occasions, the inhaled corticosteroid was increased during the first day on which the peak flow values fell, and the patients maintained the higher dose for at least 1 week. After doubling the inhaled corticosteroid, the peak flow values slowly returned towards the previous level, followed by a latter improvement in symptoms. With respect to the instruction to start oral corticosteroids when the peak flow fell to $<70 \%$, this was followed on $77 \%$ of occasions. Importantly, adherence to self-management instructions was strongly related to the severity of symptoms of asthma, with a 29,61, 79 and $100 \%$ adherence with associated symptom scores of $0,1,2$ and 3 , respectively. Although compliance with inhaled corticosteroids was not directly assessed in this study, the observation that similar doses of inhaled corticosteroids were taken before and after introduction of the self-management 
plan, suggests that the improvement in morbidity noted related to improved compliance with, rather than an increased prescribed dose of this therapy.

The other informative study is the recent long-term follow-up of the "credit card" asthma self-management plan. Two years after completion of the original study [21], the asthmatic patients were reviewed and questioned as to how they used the plan and undertook peak flow monitoring [31]. During periods of good asthma control, only $35 \%$ of patients monitored their peak flows more than once a week, whereas $81 \%$ recorded their peak flows during a severe attack. The corresponding proportion of patients who referred to their plans in these situations was 13 and 58\%, respectively. These findings suggest that after a period of initial training, when asthma control is achieved, it may be unrealistic for all asthmatic patients to measure their peak flows routinely, with its use in association with a self-management plan during deteriorating asthma representing a more appropriate use. In this study, although more patients preferred using the peak flow side of the card than the symptoms side in the situation of unstable asthma, most found both sides equally helpful, once again reinforcing the value of offering both forms of assessment.

\section{Recommendations}

In mild asthma, an initial period of assessment with recording of asthma symptoms and peak flow rates is recommended, to educate the patient to recognize changes in asthma severity, to identify those with a poor perception of asthma severity, to determine the best recorded peak flow values, and to monitor the response to the introduction of prophylactic therapy. Following this initial period, it would be possible to develop an asthma self-management plan which simply provides patients with written instructions as to when to seek medical help in the situation of a severe asthma attack. Unless the patient has a poor symptomatic perception of asthma severity, a more detailed treatment plan or the regular monitoring of peak flow is not recommended at this stage, as it is unlikely to lead to a major improvement in asthma control and is unlikely to be undertaken by the patient (even if recommended).

In patients with moderate-to-severe asthma, a similar period of assessment is recommended for the same reasons as in mild asthma, and to allow for the development of a more detailed three or four stage asthma self-management plan. It is recommended that this plan incorporates both assessment of symptoms and peak flow, with the amount of detail included depending on the requirements of the patient and the degree of medical supervision that is deemed to be necessary. Patients should be advised to use the plan preferentially during periods of unstable asthma rather than during periods of good control. Patients who are identified as being poor perceivers of asthma severity on the basis of symptoms alone are particularly encouraged to use such a self-management plan system of care.

For patients with high risk asthma, e.g. those with a recent hospital admission, a large diurnal variation of peak flow despite maximal therapy, or known brittle asthma, the regular use of peak flow monitoring and recording of symptoms in association with an asthma self-management plan is recommended, together with intensive medical and nursing supervision.

The current studies published in the European Respiratory Journal [3-5] have added to specific areas of knowledge in the clinical use of asthma self-management plans. More research into these and other aspects is undoubtedly required so that practising physicians have the necessary knowledge to produce plans that will be practical and beneficial for individual asthmatic patients under their care.

\section{References}

1. Seaton A. Asthma: contrasts in care. Thorax 1978; 33: $1-2$.

2. Lenfant C. International Consensus Report on Diagnosis and Management of Asthma. National Heart, Lung and Blood Institute, National Institutes of Health. US Department of Health and Human Services, Bethesda, USA, 1992.

3. Uwyyed K, Springer C, Avital A, Bar-Yishay E, Godfrey $\mathrm{S}$. Home recording of PEF in young asthmatics: does it contribute to management? Eur Respir J 1996; 9: 872879.

4. Verschelden P, Cartier A, L'Archevêque J, Trudeau C, Malo J-L. Compliance with and accuracy of daily selfassessment of peak expiratory flows (PEF) in asthmatic subjects over a three month period. Eur Respir J 1996; 9: 880-885.

5. Ayres JG, Campbell LM, Follows RMA on behalf of the OPTIONS research group. A controlled assessment of an asthma self-management plan involving a budesonide dose regimen. Eur Respir J 1996; 9: 886-892.

6. Rubinfeld AR, Pain MCF. Perception of asthma. Lancet 1975; ii: 822-824.

7. Burdon JGW, Juniper EF, Killian KJ, et al. The perception of breathlessness in asthma. Am Rev Respir Dis 1982; 126: 825-828.

8. Kendrick AH, Higgs CMB, Whitfield MJ, et al. Accuracy of perception of severity of asthma: patients treated in general practice. BMJ 1993; 307: 422-424.

9. Atherton HA, White PT, Hewett G, Howells K. Relationship of daytime asthma symptom frequency to morning peak expiratory flow. Eur Respir J 1996; 9: 232-236.

10. Gibson PG, Wlodarczyk J, Hensley MJ, et al. Using quality-control analysis of peak expiratory flow recordings to guide therapy for asthma. Ann Intern Med 1995; 123: 488-492.

11. Banner AS, Shad RS, Addington WW. Rapid prediction of need for hospitalisation in acute asthma. JAMA 1976; 235: 1337-1338.

12. Kelsen SE, Kelsen DP, Fleegler BF, et al. Emergency room assessment and treatment of patients with acute asthma: adequacy of the conventional approach. Am J Med 1978; 64: 622-628.

13. McFadden ER, Kiser R, De Groot WJ. Acute bronchial asthma: relations between clinical and physiological manifestations. N Engl J Med 1973; 288: 221-225.

14. Whyte MKB, Choudry NB, Ind PW. Bronchial hyperresponsiveness in patients recovering from acute severe asthma. Respir Med 1993; 87: 29-35.

15. The Diabetes Control and Complications Trial Research Group. The effect of intensive treatment of diabetes on the development and progression of long-term complications 
in insulin-dependent diabetes mellitus. $N$ Engl $\mathrm{J} \mathrm{Med}$ 1993; 329: 977-986.

16. Cochrane GM. Assessment of compliance. In: O'Byrne $\mathrm{P}$, Thomson NC, eds. Manual of Asthma Management. Philadelphia, W.B. Saunders, 1995; pp. 413-420.

17. Bailey WC, Richards JM, Brooks M, et al. A randomised trial to improve self-management practices of adults with asthma. Arch Intern Med 1990; 150: 1664-1668.

18. Mayo PH, Richman J, Harris HW. Results of a program to reduce admissions for adult asthma. Ann Intern Med 1990; 112: 864-871.

19. Beasley R, Cushley M, Holgate ST. A self-management plan in the treatment of adult asthma. Thorax 1989; 44: 200-204.

20. Charlton I, Charlton G, Broomfield J, et al. Evaluation of peak flow and symptoms only self-management plans for control of asthma in general practice. BMJ 1990; 301: 1355-1359.

21. D'Souza W, Crane J, Burgess C, et al. Community-based asthma care: trial of a "credit card" asthma self-management plan. Eur Respir J 1994; 7: 1260-1265.

22. D'Souza W, Burgess C, Crane J, et al. Trial of a credit card asthma self-management plan in a "high risk" group of asthmatics. Eur Respir J 1993; 17: 145s.

23. Mulhauser I, Richter B, Kraut D, et al. Evaluation of a structured treatment and teaching programme on asthma. J Intern Med 1991; 30: 157-164.
24. Ruffin RE, Latimer K, Schembri DA. Longitudinal study of near fatal asthma. Chest 1991; 99: 77-83.

25. Lahdensuo A, Haahtela T, Herrala J, et al. Randomised comparison of guided self-management and traditional treatment of asthma over one year. BMJ 1996; 312: $748-752$.

26. Ignacio-Garcia JM, Gonzalez-Santos P. Asthma selfmanagement education program by home monitoring of peak expiratory flow. Am J Respir Crit Care Med 1995; 151: 353-359.

27. Jones KP, Mulle MA, Middleton M, et al. Peak flow based asthma self-management: a randomised, controlled study in general practice. Thorax 1995; 50: 851857.

28. Grampian Asthma Study of Integrated Care (GRASSIC). Effectiveness of routine self-monitoring of peak flow in patients with asthma. BMJ 1994; 308: 564-567.

29. Beasley R, Burgess C, Crane J, Pearce N. Management of exacerbations of asthma in adults. In: Holgate $\mathrm{S}$, Busse W, ed. Asthma and Rhinitis. Oxford, Blackwell Scientific Press, 1994; Chp. 102, pp. 1349-1363.

30. British Thoracic Society. Guidelines on the management of asthma. Thorax 1993; 48 (Suppl.): S1-S24.

31. Te Reo o te Ora: The Wairarapa Maori Asthma Profject. Wairarapa Maori Executive/Taiwhenua o Ngati Kahunguna ki Wairarapa and the Wellington Asthma Research Group, September 1992. 